\title{
What is the impact on fish recruitment of anthropogenic physical and structural habitat change in shallow nearshore areas in temperate systems? A systematic review protocol
}

\author{
Biljana Macura ${ }^{*}$, Oona M. Lönnstedt ${ }^{2}$, Pär Byström ${ }^{3}$, Laura Airoldi ${ }^{4}$, Britas Klemens Eriksson $^{5}$, Lars Rudstam ${ }^{6}$
} and Josianne Støttrup ${ }^{7}$

\begin{abstract}
Background: Shallow nearshore marine ecosystems are changing at an increasing rate due to a range of human activities such as urbanisation and commercial development. The growing numbers of constructions and other physical and structural alterations of the shoreline often take place in nursery and spawning habitats of many fish and other aquatic species. Several coastal fish populations have seen marked declines in abundance and diversity during the past two decades. A systematic review on the topic would clarify if anthropogenic physical and structural changes of near-shore areas have effects on fish recruitment and which these effects are.

Methods: The review will examine how various physical and structural anthropogenic changes of nearshore fish habitats affect fish recruitment. Relevant studies include small- and large-scale field studies in marine and brackish systems or large lakes in temperate regions of the Northern and Southern hemispheres. Relevant studies may be based on comparisons between undisturbed and disturbed areas, before and after disturbance, or both. Relevant outcomes include measures of recruitment defined as abundance of juveniles of nearshore fish communities. Searches will be made for peer-reviewed and grey literature in English, Dutch, Danish, Finnish, German, Swedish and Spanish. All fish species and species groups will be considered in this review. Included relevant studies will be subject to a critical appraisal that will assess study validity. From relevant included studies, we will extract information on study characteristics, measured outcomes, exposure, comparators, effect modifiers and critical appraisal. Data synthesis will contain narrative and summary findings of each included study of sufficient quality. Meta-analysis may be possible in cases where studies report similar types of outcomes.
\end{abstract}

Keywords: Coastal habitat loss, Coastal development, Fish recruits, Marine infrastructure, Physical habitat change, Nursery area, Spawning ground, Young-of-the-year, YOY, Juveniles

\section{Background}

Coastal ecosystems and fish communities worldwide have undergone dramatic changes due to direct and indirect effects of anthropogenic activities [1, 2]. Human activities in shallow sheltered bays and estuaries include

\footnotetext{
${ }^{*}$ Correspondence: bmacura@gmail.com

${ }^{1}$ Mistra Council for Evidence-Based Environmental Management (EviEM), Stockholm Environment Institute, Linnégatan 87D, Box 24218, 10451 Stockholm, Sweden

Full list of author information is available at the end of the article
}

dredging, development of ports and marinas, wind farm constructions and boating, and they can all affect the availability of pristine nursery and recruitment areas [3-5]. Although several shallow nearshore areas such as bays, estuaries and wetlands have been degraded or lost [6], exact quantitative estimates of the effects on species distributions and abundances are often lacking [3, $7,8]$. These habitats serve several crucial functions, with many organisms being critically dependent on shallow coastal waters during some part of their life cycle $[4,9]$. 
In particular, shallow near-shore habitats are utilized as reproductive areas (e.g., as spawning and nursery habitats) supporting larvae and juveniles of many fish species, including several commercially important species $[8,10,11]$. For example, the historical wetland drainage in coastal Northern Europe resulted in widespread loss of crucially important recruitment areas, but smaller disturbances such as dock construction and boating have also had marked effects on shallow coastal nursery habitats [12-14].

In temperate areas, many coastal populations of fish have seen marked declines during the past two decades [15-19]. These declines have been linked to a number of factors including overexploitation, but it is becoming increasingly evident that the problem of declining abundances appears to be caused by factors affecting the early life stages of many species $[11,20]$. Indeed, several studies have documented a widespread recruitment deficit in species dependent on shallow coastal habitats for reproduction, and increased mortality during early stages has been suggested as the main cause for declining populations of adult fish [21-23]. For example, continuous declines in density and abundance of coastal top predatory fish like pike (Esox lucius) and Eurasian perch (Perca fluviatilis) have been observed since the mid-1990s in parts of the Baltic Sea [23, 24]. Correspondingly, along parts of the coast as much as $40 \%$ of the available reproductive areas were considered degraded or lost by 2005 [3]. Relationships between the size of adult fish populations and the availability and quality of recruitment habitats, along with the multitude of pressures that shorelines face, highlight the need for better understanding of how various human activities along coasts may affect fish recruitment [23, 25, 26]. Moreover, altering the abundance and diversity of large piscivorous fish may invoke community-wide trophic cascades that have far-reaching, detrimental consequences for ecosystem functioning, fisheries and human livelihoods [19, 27]. Therefore, a better understanding of how anthropogenic activities affect shallow habitats and the fish dependent on these habitats is essential for guiding management actions that aim to preserve, enhance or restore ecosystem services [2830]. Today, controversies remain as to what the primary causes of larval and juvenile fish declines are; whether anthropogenic alteration or loss of nursery coastal habitats are responsible for the declines; to what extent various habitat restoration approaches are effective; and what, if anything, can be done to reverse the declines of fish stocks $[5,12]$. However, recently, researchers have focused their attention on the links between anthropogenic pressures and fish recruitment success, and the accumulation of new data (see for example: [31-35]) suggests that a systematic review on the topic could find relevant evidence to support management actions directed towards maintaining the function of shallow nearshore and coastal areas and the conservation or restoration of fish populations.

\section{Topic identification and stakeholder input}

As a part of the Baltic Sea Action Plan, HELCOM FISHPRO II and contracting parties (http://helcom.fi/helcomat-work/projects/fish-pro) are compiling data on the status of coastal fish populations in the Baltic Sea (20132018). In 2005, the Swedish National Board of Fisheries presented a survey of recruitment problems in coastal fish populations in the Baltic Sea [11]. This survey suggested that coastal fish are disappearing during the larval or early juvenile stages. It focused on two species (perch and pike) and highlighted the inconsistencies in available data and lack of mechanistic understanding of observed patterns in the recruitment. The effects of anthropogenic disturbances on fish communities are becoming of increased national and international concern. During the formulation of the question for this review, various Swedish stakeholders (the Swedish Agency for Marine and Water Management and the Swedish University of Agricultural Sciences and representatives from the government, county boards and non-governmental organisations) highlighted the need for a comprehensive summary on how the early life stages of fish may be affected by various human activities in the Baltic Sea. A comprehensive review of the status of coastal fish populations was performed by the Helsinki Commission [10]. However, according to our knowledge, no synthesis of the evidence has been made on how the function of spawning and nursery habitats for the Baltic Sea fish populations may be affected by different anthropogenic activities. It would be useful to systematically synthesize the available literature and examine if and how direct structural changes of shorelines and nearshore aquatic areas stemming from human activities affect nursery habitats and recruitment of fish not only in the Baltic but also in other similar aquatic systems in temperate zones.

\section{Objectives of the review}

The primary objective of this review is to synthesise evidence of impact on fish recruitment of various smalland large-scale human-induced physical and structural changes in nurseries and/or spawning grounds in shallow coastal or near-shore aquatic fish habitats in the temperate zone. We focus on the Baltic Sea context. To increase statistical power and strengthen the evidence of impacts, this review will include studies from other temperate regions in both hemispheres, whilst our findings are expected to be particularly relevant to the Baltic Sea area. Therefore, we will also include evidence from 
comparable, marine and brackish temperate systems and freshwater lakes larger than $10,000 \mathrm{~km}^{2}[36,37]$. We chose a $10,000 \mathrm{~km}^{2}$ cut-off which includes lakes such as Caspian Sea and the North American Great Lake because such systems are likely to have couplings between physical and biological processes similar to those in marine systems [31, 38].

Primary question: How is fish recruitment affected by anthropogenic physical and structural habitat change in shallow nearshore areas in temperate systems?

\section{Components of the primary question:}

Population Shallow coastal or nearshore areas that are nursery and/or spawning habitats of any fish species in the temperate regions.

Exposure Direct physical and structural changes of anthropogenic origin in nursery and/or spawning fish habitats. These can be (1) small- and large-scale habitat changes caused by constructions such as ports, jetties, canals, nearshore wind farms, tidal energy facilities; (2) coastal protection structures, beach nourishment or any other shoreline modifications; (3) underwater structures such as artificial reefs, cables and pipelines; (4) habitat changes caused by extraction, land reclamation, or habitat enhancement and restoration.

Comparator No exposure.

Outcomes Any measure of recruitment success of juvenile fish, including estimates of species abundance and community composition.

Recruitment is defined as the number of individuals entering a specific life stage or reference time in a life cycle $[39,40]$. In general, the first years of life are the most dynamic phase in the life cycle of fish as (1) individuals may increase up to three orders of magnitude in size while going through dramatic morphological and functional changes and (2) mortality rates are very high but also highly variable at this stage [39, 41, 42]. Therefore, we will focus on juvenile fish, and we define recruitment in temperate systems as density and/or abundance of juvenile fish found in shallow nearshore areas. The definition of a shallow nearshore area is left relatively open as we do recognize that 'shallow' means different depths for different species and that different anthropogenic activities can affect fish habitat to different depths. However, we use the definition of 'coastal waters' from the European Water Framework Directive (L 327/6, Art.2) [43] and focus on the marine area located up to one nautical mile from the shoreline. We focus on any nearshore habitats that constitute spawning and nursery areas for juvenile fish.

\section{Methods}

\section{Search terms}

The following English language search terms will be used:
Population terms: shore", bay", coast", estuar", lagoon", lake*, intertid", nears\$hore, shallow, seagrass", seaweed", wetland", marina*, floodplain*, fiord", mudflat", saltmarsh", eelgrass", "biogenic habitat", "habitat-forming specie*", "kelp forest", "mussel bed"”, "oyster bed", "Sabellaria bed"", "sand bank", "shellfish habitat", littoral, marsh", macrophyt", "maerl bed", "habitat-engineer" species", "canopy-forming alga", "fucoid alga"”.

Exposure terms: "artificial reef", "artificial structure"," armo $\$ \mathrm{r}^{*}$, "beam trawling", cable*, dock*, drain", dredg", "habitat change"," "habitat degradation", "habitat loss", "habitat restoration", pier", pipe\$, port\$, reclamation", "wind farm"*, "wind turbine"," "ship wreck", "anthropogenic pressure", man\$made, "hydrological connectivit", "habitat connectivit", seawall", "coastal defen"”, breakwater", buoy", gabion", groyne", jett", "landing stage"*, "aggregate extraction", revetment", "hard engineering", mooring", drill", "flood gate", floodgate*, dike*, "ship channel", "shipping lane", "tidal energ"," "wave energ*", "habitat complexit"," "habitat enhancement", "habitat fragmentation", "beach nourishment".

Outcome terms: "age\$0", fish", "fish juvenile", "fish larva*", "fish nurser*", "fish recruit"” "YOY", "Young\$of\$year", "Young\$of\$the\$year", “\$group", "fish spawn", "fish reproduct"”, "CPUE", "0+fish"”, "fish abundance"," "fish densit", "fish diversit"," "fish rich"”.

We will combine the search terms within each of the three categories (population, exposure and outcome) using the Boolean operator 'OR'. We use wild-cards: for any group of characters $(*)$ or for a single character $(\$)$. We will combine the three categories into a search string using the Boolean operator 'AND'. We do not want to constrain our search to a predetermined set of exposures, and so the exposure terms include some very general search terms such as "anthropogenic pressure*", ", "habitat change"," "habitat degradation"," "habitat loss"” and "habitat restoration".

The review team tested the search string in Web of Science against a list of 20 relevant articles. The final set of search terms was the result of numerous iterative searches in Web of Science that allowed for further refinement of the search string and aimed to increase the overall comprehensiveness of the search. The full record of these iterations has been kept, and the search string can be further refined during the search.

The search string may have to be modified depending on the functionality of different databases and their search engines. In some cases, only a small number of key search terms may be used (e.g., "fish recruitment" or "fish habitat change"). Searches will also be made for studies in Dutch, Danish, Finnish, German, Swedish and Spanish. Searches performed in these languages will use set of terms corresponding to the abovementioned terms 
in English, and this will be adapted to the specific databases and their search functions.

Recorded references will be imported into an EndNote library and EPPI-Reviewer (online systematic review software). Duplicates will be deleted.

\section{Publication databases}

The search aims to include the following online databases:

1. Academic Search Premier

2. Aquatic Sciences and Fisheries Abstracts

3. Biological Abstracts

4. COPAC

5. CAB Abstracts

6. DART-Europe E thesis

7. Directory of Open-Access Journals

8. EthOS (British Library)

9. GeoBase

10. ProQuest Dissertations \& Theses

11. JSTOR

12. PiCarta

13. Scopus

14. SwePub

15. Web of Science

\section{Search engines}

An internet search will also be performed using the following search engines:

1. Google (http://www.google.com)

2. Google Scholar (http://www.scholar.google.com)

In each case, at least the first 200 hits (based on relevance) will be examined for appropriate data. Google will primarily be used for searches in non-English languages.

\section{Specialist websites}

Websites of the specialist organisations listed below will be searched for links or references to relevant publications and data, including grey literature.

1. Baltic Marine Environment Protection Commission (http://www.helcom.fi)

2. Centre for Environment, Fisheries and Aquaculture Science (http://www.cefas.co.uk)

3. Danish Centre for Environment and Energy (http:// www.dce.au.dk)

4. European Commission Joint Research Centre (http:// www.ec.europa.eu/dgs/jrc)

5. European Environment Agency (http://www.eea. europa.eu)
6. European Fisheries and Aquaculture Research Organisation (http://www.efaro.eu/)

7. FAO Fisheries and Aquaculture Department (http:// www.fao.org/fishery/en)

8. Natural Resource Institute Finland (http://www.luke. fi)

9. Finland's environmental administration (http://www. environment.fi)

10. Fisheries and Oceans Canada (www.dfo-mpo.gc.ca/ index-eng.htm) \& WAVES database (http://wavesvagues.dfo-mpo.gc.ca/waves-vagues/)

11. Great Lakes Fishery Commission (http://www.glfc. org/)

12. Greenpeace (http://www.greenpeace.org/)

13. International Council for the Exploration of the Sea (http://www.ices.dk)

14. IVL Swedish Environmental Research Institute (http://www.ivl.se)

15. National Marine Fisheries Service (http://www.nmfs. noaa.gov/)

16. Nature Conservancy (http://www.nature.org/)

17. Royal Netherlands Institute of Sea Research (http:// www.nioz.nl/home_en)

18. Senckenberg (http://www.senckenberg.de/)

19. Swedish Agency for Marine and Water Management (http://www.havochvatten.se)

20. Swedish Environment Protection Agency (http:// www.naturvardsverket.se)

21. United Nations Environment Programme (http:// www.unep.org)

22. United States Environmental Protection Agency (http://www.epa.gov)

23. World Wide Fund For Nature WWF (http://wwf. $\operatorname{org} /)$

\section{Other literature searches}

To check the comprehensiveness of our search, we will search through the bibliographies of relevant literature reviews, and all relevant references that were not captured by previous searches (if any) will be recorded and extracted. Unpublished data may be obtained from e.g. universities, consultants or local authorities involved in fish recruitment projects. Stakeholders and experts in the field will be asked to suggest relevant contacts. Members of the review team may use their contacts to find relevant grey literature on the topic, including non-English publications (in Dutch, Danish, Finnish, German, Swedish and Spanish).

\section{Screening of articles}

Publications found by the different searches will be evaluated for relevance based on the inclusion criteria at three successive levels: title, abstract and full-text. Articles 
will be first evaluated for inclusion based on their titles. This will be done by a single reviewer. To control for a reviewer's consistency, a subset of 100 titles will be assessed by at least two reviewers. The level of agreement between reviewers will be calculated by a kappa statistic. If there is an indication of inconsistency between reviewers $(\kappa<0.6)$, discrepancies will be discussed, and the inclusion criteria will be clarified or modified. Next, each publication found to be potentially relevant on the basis of its title will be judged for inclusion on the basis of its abstract. A subset of at least 100 abstracts will be assessed by at least two reviewers. The kappa statistic will be calculated, all discrepancies will be discussed, and the inclusion criteria will be clarified or modified if needed. Finally, each publication found to be potentially relevant on the basis of its abstract will be judged for inclusion by reviewers screening the full text. When uncertain, the reviewer will tend towards inclusion at each of the three screening stages. Studies or datasets found by other means than database searches may be entered at any of the two latter stages of this screening process. A list of studies rejected on the basis of full-text screening will be provided in an appendix together with the reasons for exclusion.

\section{Study inclusion criteria}

The following inclusion criteria will be applied:

Relevant subjects Any coastal or nearshore areas that may be nursery and/or spawning habitats for fish species. These habitats have to be located in temperate zones of both hemispheres, in marine and brackish systems or in lakes that are larger than $10,000 \mathrm{~km}^{2}$. To judge if a study location belongs to a temperate coastal region and can be included, we will use a map of the marine ecoregions of the world [44]. For relevant inland aquatic freshwater systems, we will use the Köppen-Geiger climate classification [45] and limit studies to warm temperate and snow climate zones in both hemispheres.

Relevant types of interventions These can be (but are not restricted to), small- and large-scale manmade structures in nearshore areas: ports, docks, jetties, canals, coastal protection structures (e.g. groynes, seawalls, revetments, rock armouring, gabions, and breakwaters); other constructions such as nearshore wind farms, and underwater nearshore structures such as artificial reefs, cables and pipelines, etc. Moreover, small- and large-scale physical changes of relevant aquatic habitats due to dredging, aggregate extraction, beach nourishment, land reclamation or habitat restoration activities will also be relevant for this review. These changes may either increase or reduce habitat complexity. Studies on barriers affecting adult fish migration and connectivity between closely adjacent freshwater reproduction habitats and the nearshore marine or large lake nursery grounds will be included for species such as percidae, esocidae and cyprinidae that use such habitats for reproduction only, but not as a yearly nursery ground. We will exclude studies that measure the effects of human activities on offshore habitats (e.g. offshore trawling). Studies that evaluate the effects of non-structural changes of the habitat, such as change of temperature or chemical structure of the aquatic system (including effects of pollution, toxicity, eutrophication or oxygen depletion), conservation policy interventions (e.g. the effects of marine protected areas), or the effects of climate change and rising sea levels on the fish stocks and do not include any measure of structural or physical habitat modifications will be excluded from this review. We will not include studies that evaluate effects of water abstractions (for aquaculture or similar purposes).

Relevant types of comparator No exposure. Studies designed as Before/After/Comparator/Intervention (BACI) include both spatial and temporal comparators and will be included in this review. Relevant studies may be also based on comparisons between undisturbed and disturbed areas (Comparator/Intervention (CI) design). Studies that compare relevant outcomes before and after of an exposure (Before/After (BA) design) will be included too. Some relevant studies may present data from a single post-disturbance sampling occasion, while others could be based on the repeated data collection over several years. In this context, we will particularly value long-term studies, since they may clarify whether anthropogenic disturbances have lasting effects or not.

Relevant types of outcome Measures of recruitment of juvenile fish, including estimates of species abundance and community composition. All fish species and species groups will be considered in this review.

Relevant types of study Any primary field study. Theoretical, modelling and laboratory-based studies will be excluded.

Language Full texts written in English, Dutch, Danish, Finnish, German, Swedish and Spanish.

\section{Potential effect modifiers and reasons for heterogeneity}

The following factors that can cause variation in measured outcomes will be considered and recorded, if available data permit:

Exposure data

1. Type and specific characteristics of an exposure

2. Timing and intensity of an exposure, including historical data 
Study design

1. Size of the study area

2. The season/period of the day when fish recruitment has been assessed

\section{Study setting}

1. Environmental characteristics of the aquatic ecosystem (e.g., salinity, temperature, transparency, dissolved oxygen, presence of pollution or toxic materials, primary productivity, etc.)

2. Habitat structure and characteristics (e.g., macrophyte community, design characteristics of artificial habitats, distance from the shore, depth, protection status)

3. Species life history and biological interactions

4. Geographical coordinates

More effect modifiers and reasons for heterogeneity may be recorded and extracted from the studies during the review process.

\section{Study quality assessment}

Included relevant studies will be subject to a critical appraisal (CA). The CA will assess study validity and categorise relevant studies as having a high, medium or low susceptibility to bias. Studies with high susceptibility to bias may be excluded from the review. The detailed criteria for the CA of included studies will be developed during the review process. The CA may consider several elements, including:

1. Level of methodological details reported;

2. Type of study design (e.g. BA/CI/BACI);

3. Temporal extent of a study (e.g. long-term or continuous versus short-term measurements);

4. Degree of accounting for potential effect modifiers;

5. Replication, pseudoreplication, and use of statistical analyses.

The decision during the critical appraisal will be recorded in a detailed and transparent manner. The quality of a study will be assessed by one reviewer. To check consistency, a subset of the studies will be appraised by the entire review team. Final decisions regarding doubtful cases will be taken by the review team as a whole. A list of studies rejected based on quality assessment will be provided in an appendix together with the reasons for exclusion.

\section{Data extraction strategy}

Data will be extracted from included studies and recorded in a spreadsheet that may include pre-determined coding. We will extract information on study characteristics, data on measured outcomes, exposure details, comparators, effect modifiers and critical appraisal. This list may be expanded during the review process depending on the type and variety of included studies. The outcome means and measures of variation (standard deviation, standard error, and confidence intervals) will be extracted from tables and graphs, using image analysis software when necessary. Where necessary, the review team will ask authors of relevant articles for access to unpublished primary data (especially where published data are presented in graphs from which it would be difficult to extract) or raw data. The review team will calculate summary statistics if the raw data are provided. All extracted data records will be made available as additional files. To test repeatability of data extraction, two independent reviewers will extract data from a subset of included studies and all entries will be compared. All disagreements among reviewers will be discussed and where necessary, coding scheme will be changed.

\section{Data synthesis and presentation}

Data synthesis will contain narrative and summary findings of each included study (of sufficient quality). A narrative data synthesis will describe the quality of the results along with the study findings. We will produce tables to summarize these results. Meta-analysis may be possible in cases where studies report similar types of outcomes. In such cases, effect sizes will be standardized (using standardized mean effect size) and weighted appropriately. Meta-regression and subgroup analysis of different study categories may be performed. Publication-bias and sensitivity analysis will also be carried out where possible. The overall effects of direct physical and structural human-induced habitat changes on fish recruitment will be presented visually in plots of mean effect sizes and variance. This review may also highlight and discuss methodological deficiencies of the relevant studies, and major knowledge gaps in the evidence base.

\section{Authors' contributions}

This systematic review protocol is based on a draft written by OML. All authors discussed the draft and suggested improvements at a meeting (29-30 October, 2015). The draft was then finalized by BM and PB with contributions from OML, LA, BKE, LR and JS. All authors read and approved the final manuscript.

\footnotetext{
Author details

${ }^{1}$ Mistra Council for Evidence-Based Environmental Management (EviEM), Stockholm Environment Institute, Linnégatan 87D, Box 24218, 10451 Stockholm, Sweden. ${ }^{2}$ Department of Ecology and Genetics, Limnology, Evolutionary Biology Centre, Uppsala University, 75236 Uppsala, Sweden. ${ }^{3}$ Department of Ecology and Environmental Science, Faculty of Science and Technology, Umeå University, 90187 Umeå, Sweden. ${ }^{4}$ Department of Biological, Geological and Environmental Sciences and Interdepartmental Research Centre for Environmental Sciences, UO CoNISMa, University of Bologna, Via S. Alberto 163, 48123 Ravenna, Italy. ${ }^{5}$ Groningen Institute for Evolutionary Life-Sciences, Marine Ecology, University of Groningen, Nijenborgh 7, 9747 AG, Groningen, The Netherlands. ${ }^{6}$ Cornell Biological Field Station, Department of Natural Resources, Cornell University, 900 Shackelton Point Road, Bridgeport, NY 13030, USA. ${ }^{7}$ National Institute of Aquatic Resources, Technical University of Denmark, Jægersborg Allé 1, 2920 Charlottenlund, Denmark.
} 


\section{Acknowledgements}

This protocol and the forthcoming review are financed by the Mistra Council for Evidence-based Environmental Management (EviEM).

\section{Competing interests}

The authors declare that they have no competing interests. The authors who also authored articles considered within this systematic review will have no direct involvement in decisions regarding inclusion or critical appraisal of these articles.

Received: 5 February 2016 Accepted: 6 May 2016

Published online: 23 May 2016

\section{References}

1. Halpern BS, Walbridge S, Selkoe KA, Kappel CV, Micheli F, D'Agrosa C, Bruno JF, Casey KS, Ebert C, Fox HE, et al. A global map of human impact on marine ecosystems. Science. 2008. doi:10.1126/science.1149345.

2. Bulleri $F$, Chapman MG. The introduction of coastal infrastructure as a driver of change in marine environments. J Appl Ecol. 2010. doi:10.1111/j.1365-2664.2009.01751.x.

3. Sundblad G, Bergström U. Shoreline development and degradation of coastal fish reproduction habitats. Ambio. 2014. doi:10.1007/ s13280-014-0522-y.

4. Beck MW, Heck KL, Able KW, Childers DL, Eggleston DB, Gillanders BM, Halpern B, Hays CG, Hoshino K, Minello TJ, et al. The identification, conservation, and management of estuarine and marine nurseries for fish and invertebrates. Bioscience. 2001. doi:10.1641/0006-3568(2001)051[0633:TIC $\mathrm{AMO}$ 2.0.CO;2.

5. Larsson P, Tibblin P, Koch-Schmidt P, Engstedt O, Nilsson J, Nordah $\mathrm{O}$, Forsman A. Ecology, evolution, and management strategies of northern pike populations in the Baltic Sea. Ambio. 2015. doi:10.1007/ s13280-015-0664-6.

6. Airoldi L, Beck MW. Loss, status and trends for coastal marine habitats of Europe. In: Gibson, RN, Atkinson, RJA, Gordon, JDM, editors. Oceanography and Marine Biology. Vol 45; 2007. p. 345-405.

7. Lotze HK. Historical reconstruction of human-induced changes in US estuaries. Oceanogr Mar Biol Annu Rev. 2010;48:267-338.

8. Lotze HK, Lenihan HS, Bourque BJ, Bradbury RH, Cooke RG, Kay MC, Kidwell SM, Kirby MX, Peterson CH, Jackson JBC. Depletion, degradation, and recovery potential of estuaries and coastal seas. Science. 2006;312:1806-9.

9. Seitz RD, Wennhage H, Bergström U, Lipcius RN, Ysebaert T. Ecological value of coastal habitats for commercially and ecologically important species. ICES J Mar Sci. 2014. doi:10.1093/icesjms/fst152.

10. HELCOM. Ecosystem health of the Baltic Sea: HELCOM Initial Holistic Assessment. Baltic Sea Environment Proceedings; 2010.p.1-63.

11. Ljunggren L, Sandstrom A, Johansson G, Sundblad G, Karas P. Problems of recruitment in Baltic Sea fish stocks. Finfo Fiskeriverket Informerar. 2005:5:1-45.

12. Sandström A, Eriksson BK, Karås $P$, Isæus M, Schreiber H. Boating and navigation activities influence the recruitment of fish in a Baltic Sea Archipelago Area. Ambio. 2005. doi:10.1579/0044-7447-34.2.125.

13. Nilsson J, Engstedt O, Larsson P. Wetlands for northern pike (Esox lucius L.) recruitment in the Baltic Sea. Hydrobiologia. 2014. doi:10.1007/ s10750-013-1656-9.

14. Eriksson BK, Sandstrom A, Isæus M, Schreiber H, Karas P. Effects of boating activities on aquatic vegetation in the Stockholm archipelago, Baltic Sea. Estaur Coast Shelf Sci. 2004:61:339-49.

15. ICES. Report of the Baltic Fisheries Assessment Working Group (WGBFAS). ICES CM 2014/ACOM: 10. 2014.

16. Olsson J, Bergström L, Gårdmark A. Abiotic drivers of coastal fish community change during four decades in the Baltic Sea. ICES J Mar Sci. 2012. doi:10.1093/icesjms/fss072.

17. Adjers K, Appelberg M, Eschbaum R, Lappalainen A, Minde A, Repecka R, Thoresson G. Trends in coastal fish stocks of the Baltic Sea. Boreal Environ Res. 2006;11:13-25.

18. Tulp I, Bolle $L$, Rlinsdorp AD. Signals from the shallows: in search of common patterns in long-term trends in Dutch estuarine and coastal fish. J Sea Res. 2008:60:54-73.
19. Eriksson BK, Sieben K, Eklöf J, Ljunggren L, Olsson J, Casini M, Bergström $U$. Effects of altered offshore food webs on coastal ecosystems emphasize the need for cross-ecosystem management. Ambio. 2011. doi:10.1007/ s13280-011-0158-0.

20. Andersson J, Dahl J, Johansson A, Karås P, Nilsson J, Sandström O, Svensson P. Utslagen fiskrekrytering och sviktande fiskbestånd i Kalmar läns kustvatten. [English title: Recruitment failure and decreasing fish stocks in the coastal areas of Kalmarsund]. Fiskeriverket Rapport. 2000;5:3-42.

21. Lehtonen H, Leskinen E, SelÉN R, Reinikainen M. Potential reasons for the changes in the abundance of pike, Esox lucius, in the western Gulf of Finland, 1939-2007. Fish Manage Ecol. 2009. doi:10.1111/j.1365-2400.2009.00701.x.

22. Nilsson J, Andersson J, Karas P, Sandstrom O. Recruitment failure and decreasing catches of perch (Perca fluviatilis L.) and pike (Esox lucius L.) in the coastal waters of southeast Sweden. Boreal. Environ Res. 2004:9:295-306.

23. Sundblad G, Bergström U, Sandström A, Eklöv P. Nursery habitat availability limits adult stock sizes of predatory coastal fish. ICES J Mar Sci. 2014. doi:10.1093/icesjms/fst056.

24. Ljunggren L, Sandström A, Bergström U, Mattila J, Lappalainen A, Johansson G, Sundblad G, Casini M, Kaljuste O, Eriksson BK. Recruitment failure of coastal predatory fish in the Baltic Sea coincident with an offshore ecosystem regime shift. ICES J Mar Sci: Journal du Conseil. 2010. doi:10.1093/ icesjms/fsq109.

25. Halpern BS, Gaines SD, Warner RR. Habitat Size, recruitment, and longevity as factors limiting population size in stage-structured species. Am Nat. 2005:165:82-94.

26. Ljunggren L, Olsson J, Nilsson J, Stenroth P, Larsson P, Engstedt O, Borger $\mathrm{T}$, Sandstrom O. Water courses as recruitment areas for pike in the Baltic Sea. Experiences and recommendations from the research project. Finfo Fiskeriverket Informerar. 2011:1:1-63.

27. Jackson JBC, Kirby MX, Berger WH, Bjorndal KA, Botsford LW, Bourque BJ, Bradbury RH, Cooke R, Erlandson J, Estes JA, et al. Historical overfishing and the recent collapse of coastal ecosystems. Science. 2001. doi:10.1126/science.1059199.

28. Rönnbäck P, Kautsky N, Pihl L, Troell M, Söderqvist T, Wennhage H. Ecosystem goods and services from Swedish coastal habitats: identification, valuation, and implications of ecosystem shifts. Ambio. 2007 doi:10.1579/0044-7447(2007)36[534:EGASFS]2.0.CO;2.

29. Stål J, Paulsen S, Pihl L, Rönnbäck P, Söderqvist T, Wennhage H. Coastal habitat support to fish and fisheries in Sweden: integrating ecosystem functions into fisheries management. Ocean Coast Manag. 2008. doi:10.1016/j.ocecoaman.2008.06.006.

30. Abelson A, Halpern BS, Reed DC, Orth RJ, Kendrick GA, Beck MW Belmaker J, Krause G, Edgar GJ, Airoldi L, et al. Restoration of marine ecosystems: a need for ecological-social concept upgrade. Bioscience. 2016;66:156-63.

31. Pritt JJ, Roseman EF, O'Brien TP. Mechanisms driving recruitment variability in fish: comparisons between the Laurentian Great Lakes and marine systems. ICES J Mar Sci. 2014;71:2252-67.

32. Dauble AD, Heppell SA, Johansson ML. Settlement patterns of youngof-the-year rockfish among six Oregon estuaries experiencing different levels of human development. Mar Ecol Prog Ser. 2012. doi:10.3354/ meps09504.

33. Obaza A, Hoffman R, Clausing R. Long-term stability of eelgrass fish assemblages in two highly developed coastal estuaries. Fish Manage Ecol. 2015:22:224-38

34. Pereira HH, Neves LM, da Costa MR, Araújo FG. Fish assemblage structure on sandy beaches with different anthropogenic influences and proximity of spawning grounds. Mar Ecol Evol Perspect. 2015;36:16-27.

35. Sheehan EV, Gall SC, Cousens SL, Attrill MJ, Stevens TF. Recovery of a temperate reef assemblage in a marine protected area following the exclusion of towed demersal fishing. PLOS ONE. 2013. doi:10.1371/journal.pone.0083883.

36. Kalff J. Limnology: inland water ecosystems. NJ Prentice Hall: Upper Saddle River; 2002

37. Tyus HM. Ecology and conservation of fishes. London: CRC Press; 2012.

38. Ludsin SA, DeVanna KM, Smith REH. Physical-biological coupling and the challenge of understanding fish recruitment in freshwater lakes. Can J Fish Aquat Sci. 2014. doi:10.1139/cjfas-2013-0512. 
39. Chambers RC, Trippel EA. Early life history and recruitment in fish populations. London: Chapman and Hall; 1997.

40. Caley MJ, Carr MH, Hixon MA, Hughes TP, Jones GP, Menge BA. Recruitment and the local dynamics of open marine populations. Ann Rev Ecol Systemat. 1996;27:477-500

41. Miller TJ, Crowder LB, Rice JA, Marschall EA. Larval size and recruitment mechanisms in fishes: towards a conseptual framework. Can J Fisheries Aquat Sci. 1988;45:1657-70.

42. Werner EE. Size, scaling and the evolution of complex life cycles. In: Ebenman B, Persson L, editors. Size-structured populations: ecology and evolution. Berlin: Springer-Verlag; 1988. p. 60-81.
43. EC.Directive $2000 / 60 / E C$ of the European Parliament and of the Counci of October 23, 2000 establishing a framework for community action in the field of water policy ( $\mathrm{L} 327$ of 22-12-2000).

44. Spalding MD, Fox HE, Allen GR, Davidson N, Ferdaña ZA, Finlayson M, Halpern BS, AI Lombana MAJ, Lourie SA, Martin KD, et al. Marine ecoregions of the world: a bioregionalization of coastal and shelf areas. Bioscience. 2007. doi:10.1641/B570707.

45. Kottek M, Grieser J, Beck C, Rudolf B, Rubel F. WorldMap of the KöppenGeiger climate classification updated. Meteorol Z. 2006;15:259-63.

\section{Submit your next manuscript to BioMed Central and we will help you at every step:}

- We accept pre-submission inquiries

- Our selector tool helps you to find the most relevant journal

- We provide round the clock customer support

- Convenient online submission

- Thorough peer review

- Inclusion in PubMed and all major indexing services

- Maximum visibility for your research

Submit your manuscript at

www.biomedcentral com/submit 